\title{
Mechanisms by Which Different Functional States of Mitochondria Define Yeast Longevity
}

\author{
Adam Beach ${ }^{\dagger}$, Anna Leonov ${ }^{\dagger}$, Anthony Arlia-Ciommo ${ }^{\dagger}$, Veronika Svistkova ${ }^{\dagger}$, Vicky Lutchman ${ }^{\dagger}$ \\ and Vladimir I. Titorenko * \\ Department of Biology, Concordia University, 7141 Sherbrooke Street, West, SP Building, \\ Room 501-13, Montreal, QC H4B 1R6, Canada; E-Mails: adam.pb.beach@gmail.com (A.B.); \\ anna_leonova@yahoo.com (A.L.); anthony.arlia@outlook.com (A.A.-C.); \\ klubnika_veronika@hotmail.com (V.S.); lutchman.david@hotmail.com (V.L.) \\ $\dagger$ These authors contributed equally to this work. \\ * Author to whom correspondence should be addressed; E-Mail: vladimir.titorenko@concordia.ca; \\ Tel.: +1-514-848-2424 (ext. 3424); Fax: +1-514-848-2881.
}

Academic Editor: Bing Yan

Received: 2 February 2015 / Accepted: 5 March 2015 / Published: 11 March 2015

\begin{abstract}
Mitochondrial functionality is vital to organismal physiology. A body of evidence supports the notion that an age-related progressive decline in mitochondrial function is a hallmark of cellular and organismal aging in evolutionarily distant eukaryotes. Studies of the baker's yeast Saccharomyces cerevisiae, a unicellular eukaryote, have led to discoveries of genes, signaling pathways and chemical compounds that modulate longevity-defining cellular processes in eukaryotic organisms across phyla. These studies have provided deep insights into mechanistic links that exist between different traits of mitochondrial functionality and cellular aging. The molecular mechanisms underlying the essential role of mitochondria as signaling organelles in yeast aging have begun to emerge. In this review, we discuss recent progress in understanding mechanisms by which different functional states of mitochondria define yeast longevity, outline the most important unanswered questions and suggest directions for future research.
\end{abstract}

Keywords: yeast; cellular aging; longevity regulation; metabolism; interorganellar communications; mitochondria; mitochondrial respiration; mitochondrial membrane potential; mitochondrial reactive oxygen species; mitochondrial lipidome 


\section{Introduction}

The functional state of mitochondria is crucial for organismal physiology in all eukaryotes [1-5]. This is in part because mitochondria produce the bulk of cellular ATP and synthesize (or generate biosynthetic intermediates for) amino acids, lipids and nucleotides [3-7]. This is also because mitochondria can operate as intracellular signaling compartments and organizing platforms whose different functional states and dynamic communications with other organelles orchestrate a range of cellular responses to changes in various physiological conditions [1,3,5,7-28]. Several mechanistically diverse strategies have been implicated in enabling mitochondria to function as such signaling compartments and organizing platforms within eukaryotic cells; these strategies are depicted in Figure 1 and outlined below.

First strategy: mitochondria can respond to variations in cellular energy status by altering $\mathrm{NAD}^{+} / \mathrm{NADH}$, AMP/ATP and acetyl-CoA/CoA ratios inside and outside of these organelles [3,23,29] (Figure 1). Such alterations in the relative levels of the key mitochondria-derived metabolites modulate activities of several protein sensors (including sirtuins Sirt1, Sirt3 and Sirt5 as well as the AMP-activated protein kinase and histone acetyltransferase GCN5), which then amend the extent of acetylation and phosphorylation (and thereby activities) of many downstream protein targets; this elicits a remodeling of a network of anabolic and catabolic pathways defining cellular energy status [3,19,23,29-38].

Second strategy: mitochondria can generate reactive oxygen species (ROS) — mainly as by-products of mitochondrial respiration in all eukaryotes, but also via oxidation of cytochrome $c$ by the inter-membrane space protein $\mathrm{p} 66^{\mathrm{shc}}$ in mice [39-41] (Figure 1). If the concentration of ROS released from mitochondria exceeds a toxic threshold, ROS impair many vital cellular processes by eliciting health-demoting oxidative damage to proteins, lipids and nucleic acids in various cellular locations [39-43]. However, if the concentration of ROS released from mitochondria is sustained at a sub-lethal (hormetic) level, ROS operate as potent signaling molecules that modulate activities of some protein sensors [18,19,39,42-47]. Among these ROS-modulated sensors are several protein kinases, transcription factors and antioxidant enzymes; they respond to ROS by altering activities of a network of downstream protein targets to stimulate a number of vital health-promoting cellular processes [18,19,39,42-53].

Third strategy: mitochondria can synthesize and assemble iron-sulfur clusters (ISC); ISC are cofactors of many proteins that reside in mitochondria as well as in the cytosol, nucleus and endoplasmic reticulum (ER) [54-59] (Figure 1). Mitochondrial ISC proteins are essential components of the tricarboxylic acid (TCA) cycle and electron transport chain (ETC); they are also involved in the synthesis of some amino acids, heme, molybdenum cofactor, lipoic acid and biotin within mitochondria [54-59]. Cytosolic ISC proteins have been implicated in nucleotide metabolism, amino acid synthesis, iron homeostasis regulation, xenobiotic metabolism, translation initiation, tRNA modification and receptor tyrosine kinase signaling [54-59]. Nuclear ISC proteins function in DNA replication and repair, telomere maintenance, gene expression regulation, rRNA processing, and ribosome assembly [54-63].

Fourth strategy: mitochondria can respond to various stress conditions inside and outside of these organelles by releasing signaling peptides, proteins, mitochondrial DNA (mtDNA) and mtDNA fragments that act intracellularly and extracellularly to elicit cellular and organismal responses to such conditions (Figure 1). These mitochondria-derived stress signaling macromolecules include the following: (1) peptides formed due to the proteolytic degradation of unfolded and misfolded proteins excessively accumulated within the mitochondrial matrix; after being released from mitochondria, these 
peptides trigger several unfolded protein response (UPR ${ }^{\mathrm{mt}}$ ) pathways of mitochondria-to-nucleus communications that stimulate transcription of nuclear genes involved in mitochondrial quality control and metabolism [18,19,53,64-73]; (2) humanin, an $N$-formylated peptide; after being synthesized and released by dysfunctional mitochondria in the "host" cells, humanin acts in a cell-autonomous manner to suppress apoptosis of these cells as well as in a cell-non-autonomous fashion to promote survival, reduce inflammation and maintain metabolic homeostasis of the distal cells in other tissues [72,74-81]; (3) signaling macromolecules that belong to the "mitochondrial damage-associated molecular pattern" (mitochondrial DAMP or MTD) family and include some $N$-formylated peptides, several proteins, mtDNA and mtDNA fragments; these MTDs function cell-autonomously and cell-non-autonomously to stimulate inflammation and elicit innate immune response by activating transcription of nuclear genes coding for pro-inflammatory cytokines [10,12,72,82-89]; (4) cytochrome $c$ and other pro-apoptotic proteins; after being released from mitochondria in excessively stressed cells, these mitochondria-derived proteins either trigger caspase-dependent and caspase-independent pathways of programmed apoptotic cell death or control such non-apoptotic processes as cell metabolism, cell cycle progression, inflammation, innate immune response, autophagy and programmed necrotic cell death $[3,9,10,12,13,16,17,23,24] ;$ (5) the pyruvate dehydrogenase complex, which in cultured human cells exposed to serum, epidermal growth factor or mitochondrial stress can move from the mitochondria to the nucleus to synthesize acetyl-CoA used for histone acetylation, S phase entry and cell-cycle progression [90]; and (6) mitokines in the nematode Caenorhabditis elegans; after these diffusible factors of unknown chemical nature exit mildly stressed mitochondria in neuronal cells, they act in an endocrine-like fashion to activate the longevity-extending UPR ${ }^{\mathrm{mt}}$ pathway of mitochondria-to-nucleus communication in intestinal cells $[72,91,92]$.

Fifth strategy: the surface of mitochondria can provide an organizing platform for assembly and disassembly of several multi-protein complexes (Figure 1). A regulated remodeling of these protein complexes on the outer face of mitochondria has been implicated in many vital processes, including (1) cell metabolism, signaling, immune response, hypoxic response, differentiation and death; and (2) mitochondrial fusion, fission, motility, inheritance, autophagic degradation and DNA maintenance $[1,3,9,14,16,21-24,26,93-99]$.

Sixth strategy: the mitochondrial outer membrane can form zones of close apposition to the mitochondria-associated membrane (MAM) domains of other organellar and cellular membranes, including the ER, peroxisomes, vacuoles, autophagosomes, melanosomes and plasma membrane [3,27,28,100-108] (Figure 1). The MAM domains are known to play essential roles in ATP and ROS production, mitochondrial biogenesis and morphology, mitochondrial fission and motility, ER stress regulation, cellular $\mathrm{Ca}^{2+}$ homeostasis, membrane phospholipids metabolism and transfer, autophagosome biogenesis, innate immune and inflammatory responses, and programmed apoptotic cell death [3,16,18,21,24-28,100-115].

Seventh strategy: mitochondria can form small vesicles that transport distinct subsets of mitochondrial proteins and lipids to peroxisomes and lysosomes (Figure 1). Such vesicular transport of mitochondria-derived protein and lipid cargos has been implicated in mitochondrial quality control; it may also play a role in peroxisome biogenesis and function [116-121]. 


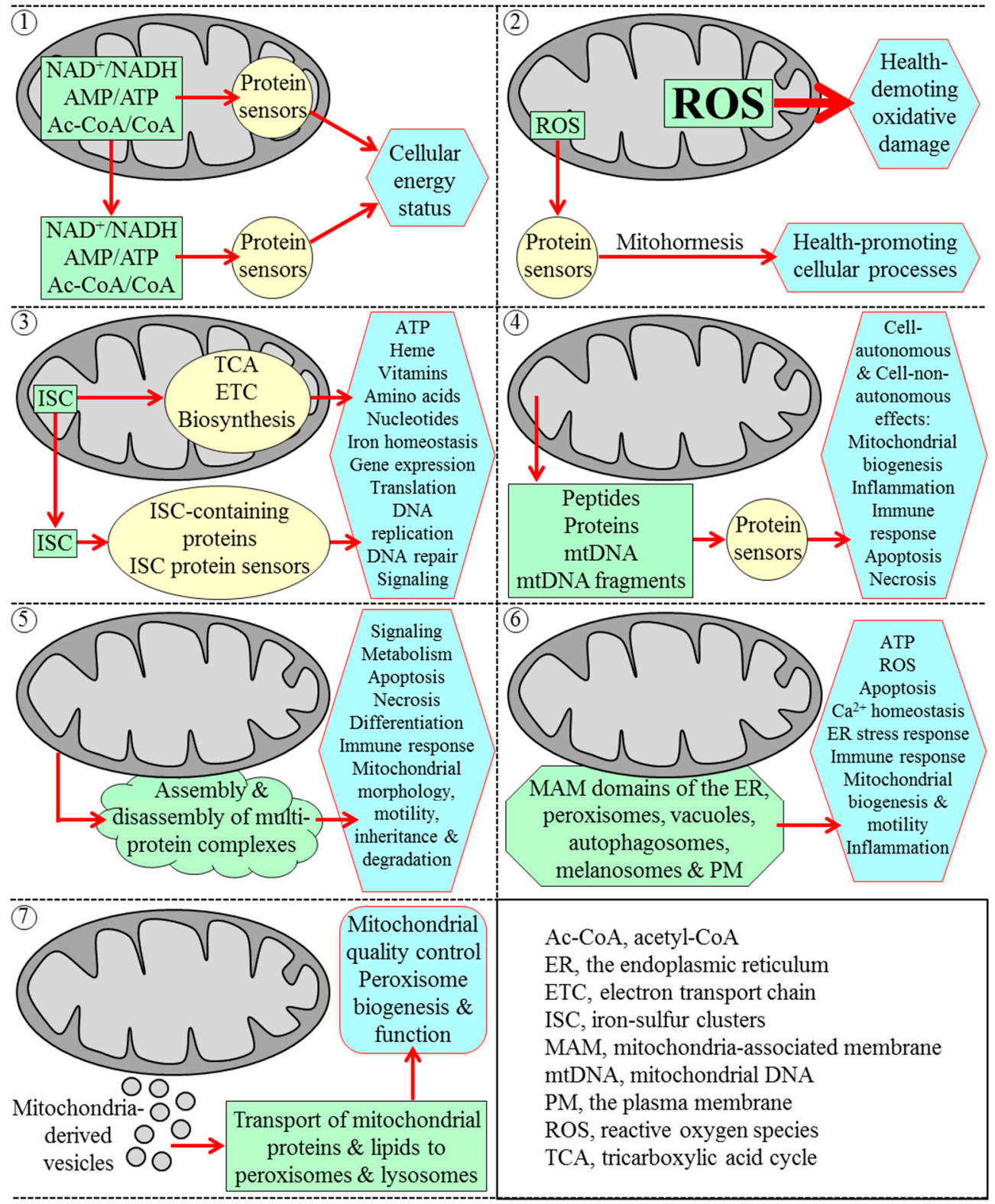

Figure 1. Seven strategies allow mitochondria to operate as intracellular signaling compartments and organizing platforms that orchestrate cellular responses to changes in physiological conditions. Strategy 1: mitochondria can change $\mathrm{NAD}^{+} / \mathrm{NADH}, \mathrm{AMP} / \mathrm{ATP}$ and acetyl-CoA/CoA ratios inside and outside of mitochondria, thus enabling these key metabolites to modulate activities of several protein sensors. These sensors then alter cellular energy status by amending activities of proteins involved in various metabolic pathways; Strategy 2: mitochondria can generate and release reactive oxygen species (ROS). If the concentration of ROS released from mitochondria surpasses a toxic threshold, ROS cause health-demoting oxidative damage to cellular macromolecules. In contrast, if it is maintained at a sub-lethal (hormetic) level, ROS modulate activities of several protein sensors, which then alter activities of many protein targets to accelerate health-promoting cellular processes; Strategy 3: mitochondria can synthesize and assemble iron-sulfur clusters (ISC). ISC are essential cofactors of numerous proteins located inside and outside of mitochondria; these proteins are involved in many cellular processes; Strategy 4: 
mitochondria can release peptides, proteins, mitochondrial DNA (mtDNA) and mtDNA fragments. These mitochondria-derived signaling macromolecules act in a cell-autonomous and cell-non-autonomous manner to elicit changes in vital processes that take place in the "host" cells and within the distal cells in other tissues; Strategy 5: mitochondrial surface can serve as an organizing platform for assembly and disassembly of multi-protein complexes implicated in a number of essential processes; Strategy 6: mitochondria can form zones of close apposition to the mitochondria-associated membrane (MAM) domains of other organellar and cellular membranes. These MAM domains are known for their essential roles in many cellular processes; Strategy 7: mitochondria can form small vesicles. These vesicles deliver certain proteins and lipids to lysosomes and peroxisomes, thereby enabling mitochondrial quality control and playing a role in peroxisome biogenesis and function. See the text for additional details.

Because mitochondrial functionality is vital to organismal physiology and health, mitochondrial dysfunction is a cause of numerous human mitochondrial disorders; these inborn disorders are due to mutations in nuclear genes and/or mtDNA, affect various tissues and organs, and exhibit a wide spectrum of clinical features [3,4,122-125]. Furthermore, mitochondrial dysfunction has been implicated in a variety of common human disorders, such as metabolic syndrome, obesity, type 2 diabetes, cardiomyopathies, neurodegenerative disorders and cancer [3,5,10,15,34,126-131]. Most of these common human disorders are aging-associated pathologies; moreover, a gradual deterioration of mitochondrial function is a distinctive and, likely, a causative feature of aging in eukaryotic organisms across phyla $[2,10,18,19,132,133]$. Therefore, an age-related progressive decline in mitochondrial function is considered as one of the hallmarks of cellular and organismal aging in evolutionarily distant eukaryotes [133]. Studies of the baker's yeast Saccharomyces cerevisiae, a unicellular eukaryote, have provided deep insights into mechanisms linking mitochondrial functionality and cellular aging [2,18-20,134-140]. In this review, we discuss recent progress in understanding such mechanisms.

\section{The Yeast S. cerevisiae Is a Beneficial Model Organism for Uncovering Mechanisms of Cellular Aging in Multicellular Eukaryotes}

Aging of baker's yeast is studied using robust assays. These assays are carried out under controllable laboratory conditions and measure two different aspects of the aging process in $S$. cerevisiae. Some of these assays monitor the replicative lifespan of yeast by measuring how many asymmetric mitotic divisions a mother cell could undergo before cell cycle arrest; replicative aging of yeast is believed to model aging of mitotic (i.e., capable of dividing) human cell types, such as fibroblasts, granulocytes, monocytes, lymphocytes and stem cells from amniotic fluid [137,141-144]. Other assays monitor the chronological lifespan of yeast by measuring how long a cell remains viable after cell cycle arrest; chronological aging of yeast is likely to mimic aging of post-mitotic (i.e., incapable of dividing) human cell types, such as mature neurons, adipocytes and mature muscle cells [137,143,145-147]. S. cerevisiae has relatively short replicative and chronological lifespans; moreover, it is amenable to comprehensive biochemical, molecular biological and cell biological analyses [137,142,146,148-151]. Because of these beneficial features of $S$. cerevisiae as a model for unveiling mechanisms of aging in multicellular 
eukaryotes, the use of the baker's yeast has enabled to discover genes, signaling pathways and chemical compounds that govern longevity-defining cellular processes in eukaryotic organisms across phyla $[18-20,137,143,144,146,147,150,152-162]$.

\section{Mitochondria Are Signaling Organelles that Establish the Rate of Cellular Aging in Yeast by Orchestrating Many Processes Outside of Mitochondria}

A body of recent evidence implies that alterations in certain traits of mitochondrial functionality early in life of replicatively or chronologically aging yeast impact many cellular processes outside of mitochondria, thereby orchestrating a stepwise development of a longevity-defining cellular pattern and its maintenance throughout lifespan. The molecular mechanisms underlying the essential role of mitochondria as signaling organelles in yeast aging have begun to emerge; they involve unidirectional and bidirectional communications between mitochondria and other cellular compartments. In this section, we discuss such mechanisms.

\subsection{Mechanisms Underlying the Essential Role of Mitochondria in Yeast Replicative Aging}

A mitotically competent mother yeast cell progresses through three consecutive stages of replicative aging before becoming unable to produce daughter cells; these stages are called "early age", "intermediate age" and "late age" [20,144]. Characteristic features of the intermediate-age stage of replicative aging include a decline in mitochondrial respiration and the resulting reduction of mitochondrial membrane potential [20,144,163] (Figure 2A). A replicatively aging mother yeast cell responds to such reduction of mitochondrial membrane potential by activating the Rtg2 protein in the cytosol; a mechanism underlying such activation remains to be established $[136,138,164]$. Rtg2 is essential for reducing the rate of yeast replicative aging because this protein (1) triggers the mitochondrial retrograde signaling pathway by stimulating nuclear import of the Rtg1-Rtg3 heterodimeric transcription factor; this factor then orchestrates an anti-aging transcriptional program by activating expression of many nuclear genes involved in carbohydrate and nitrogen metabolism, peroxisomal fatty acid oxidation and anaplerotic reactions, peroxisome proliferation, stabilization of nuclear and mitochondrial genomes, and stress response [136,138,164]; and (2) is imported into the nucleus, where it increases genome stability and also slows down the synthesis of extrachromosomal rDNA circles known to be one of the "aging factors" limiting the replicative lifespan of the mother cell $[136,138,164]$ (Figure 2A). The reduction of mitochondrial membrane potential during the intermediate-age stage of replicative aging slows down the aging process not only by activating the two Rtg2-driven mechanisms but also by inhibiting the target of rapamycin (TOR) complex 1 protein kinase activity [136,138,164] (Figure 2A); a mechanism of such inhibition of this key component of the pro-aging TOR signaling pathway is unknown. Moreover, the decline in mitochondrial membrane potential during the intermediate-age stage of replicative aging also decelerates mitochondrial synthesis of ISC and/or slows down their efflux from mitochondria [60] (Figure 2A). Because ISC are essential cofactors of nuclear proteins that in yeast are involved in DNA replication, DNA repair and telomere maintenance, their reduced quantity in replicatively aging yeast compromises genome integrity $[18,20,60,62]$. Moreover, because ISC mitigate activity and/or decelerate nuclear import of the transcription activator Aft1, their reduced quantity in replicatively aging yeast allows Aft1 to stimulate 
expression of nuclear genes needed for iron entry into and distribution within the cell; the ensuing rise in free intracellular iron accelerates replicative aging by promoting iron-driven oxidative damage of many cellular proteins $[18,56,60]$.

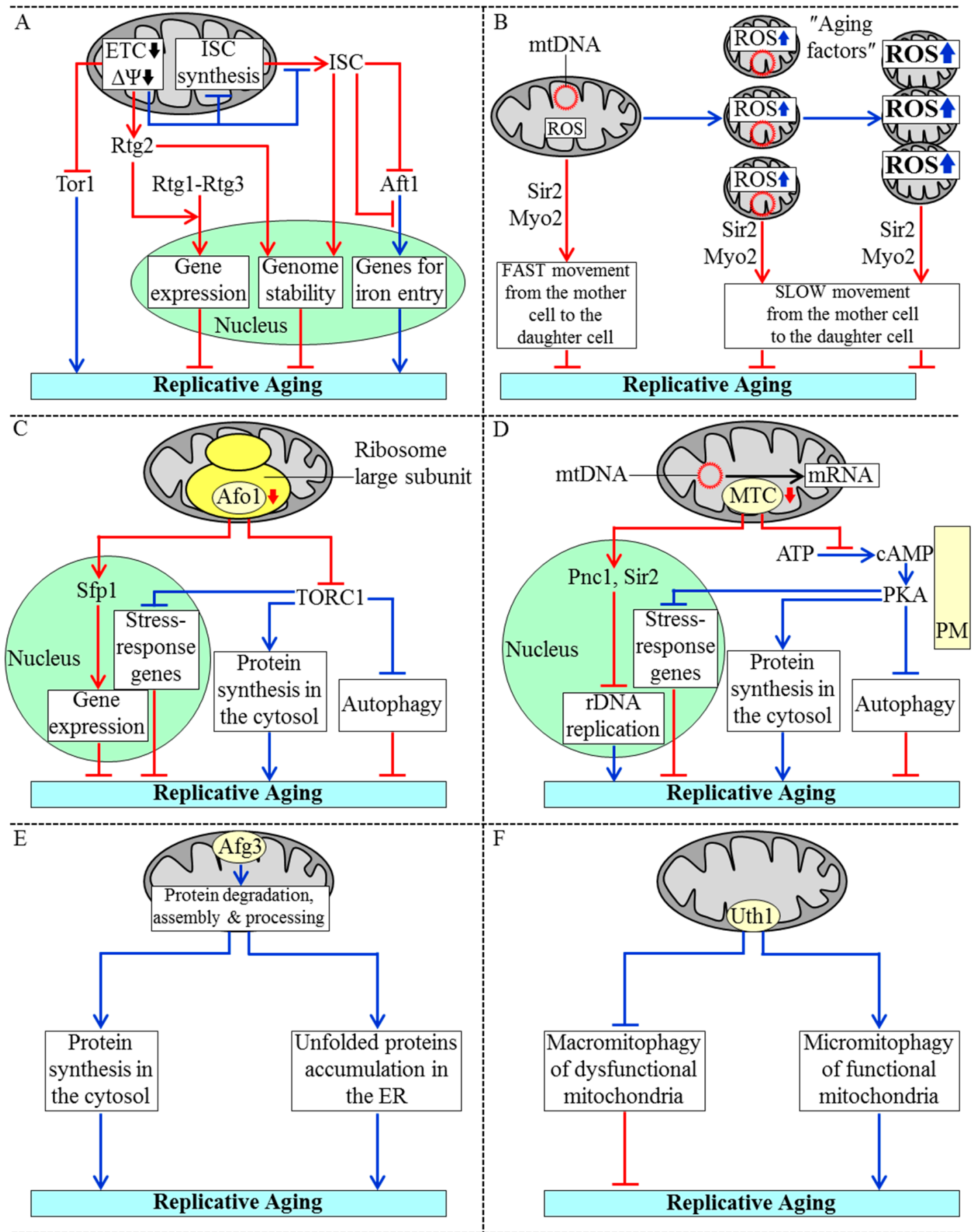

Figure 2. Mechanisms underlying the essential role of mitochondria in yeast replicative aging. (A) A decline in the mitochondrial electron transport chain (ETC) and the resulting reduction of mitochondrial membrane potential $(\Delta \Psi)$ delay replicative aging in yeast by: (1) stimulating Rtg2-dependent nuclear import of the Rtg1-Rtg3 heterodimeric transcription factor, thereby activating the mitochondrial retrograde signaling pathway; (2) promoting the import of Rtg2 into the nucleus, where it increases genome stability; and (3) reducing a protein kinase activity of the target of rapamycin protein 1 (Tor1). The reduction of $\Delta \Psi$ 
also attenuates mitochondrial synthesis and/or export of iron-sulfur clusters (ISC), which are needed for maintaining genome stability and inhibiting the Aft1-driven transcription of nuclear genes involved in iron entry into the cell; (B) A transition from the early-age stage to the intermediate-age stage of replicative aging coincides with a rise of mitochondrial reactive oxygen species (ROS) and fragmentation of mitochondria in the mother cell; these fragmented mitochondria produce more ROS, aggregate and lose mitochondrial DNA (mtDNA) during the subsequent late-age stage of replicative aging. The dysfunctional mitochondria formed during the intermediate-age and late-age stages of replicative aging are so-called "aging factors". They limit the replicative lifespan of the mother cell; their Sir2- and Myo2-driven movement to the daughter cell occurs slower than that of fully functional mitochondria; (C) A reduction in the quantity of the Afol protein component of the large subunit of the mitochondrial ribosome delays replicative aging in yeast by: (1) stimulating Sfp1-driven transcription of nuclear genes encoding protein components of cytoplasmic ribosomes; and (2) attenuating the TOR signaling pathway, which accelerates the pro-aging process of protein synthesis in the cytosol and also slows down the anti-aging processes of autophagy and transcription of stress-response genes in the nucleus; (D) Mitochondrial translation control (MTC) proteins assist in processing, stabilization and translation of mRNAs encoded by mtDNA. A reduction in the quantity of MTC proteins slows down replicative aging in yeast by: (1) triggering the Pnc1- and Sir2-dependent inhibition of the synthesis of extrachromosomal rDNA circles; and (2) reducing the cellular concentration of cAMP and thus attenuating the cAMP-dependent protein kinase A (PKA) activity, which decelerates the anti-aging processes of autophagy and transcription of stress-response genes in the nucleus and also accelerates the pro-aging process of protein synthesis in the cytosol; (E) Afg3 is a mitochondrial protease involved in maintaining protein homeostasis (proteostasis) in mitochondria. The Afg3-driven processes in mitochondria include degradation of misfolded proteins, assembly of ETC protein complexes and processing of a protein component of the large subunit of the mitochondrial ribosome; these proteostatic processes within mitochondria stimulate such pro-aging processes outside of these organelles as protein synthesis in the cytosol and the accumulation of unfolded proteins in the endoplasmic reticulum (ER); (F) The Uth1 protein in the mitochondrial outer membrane is a pro-aging factor that accelerates replicative aging in yeast by concurrently weakening macromitophagic degradation of dysfunctional mitochondria and enhancing micromitophagic degradation of functional mitochondria. Activation arrows and inhibition bars denote pro-aging processes (displayed in blue color) or anti-aging processes (displayed in red color). See the text for additional details.

During the intermediate-age stage of replicative aging, mitochondria in the mother cell not only exhibit reduced membrane potential but also generate elevated quantities of ROS and undergo fragmentation; during the subsequent late-age stage of replicative aging, the functionality of mitochondria is further declined as these organelles accumulate excessive levels of ROS, aggregate and fail to keep mtDNA [18,20,144,163,165-168] (Figure 2B). The dysfunctional mitochondria exhibiting these age-related traits of deteriorated functionality are known to be one of the aging factors limiting the 
replicative lifespan of the mother cell [20,137,141,144,161,163]. A mechanism exists for retaining these dysfunctional mitochondria within the mother cell, thus preventing their transmission into the daughter cell. In this mechanism, the dysfunctional mitochondria move from the mother cell to the daughter cell slower than their fully functional counterparts; such movement of mitochondria on actin cables is driven by the sirtuin Sir2 and type V myosin motor Myo2 [20,165,169-171] (Figure 2B).

The rate of yeast replicative aging is also modulated by the quantity of the Afol protein component of the large subunit of the mitochondrial ribosome; such modulation is not due to an effect of variations in Afol quantities on the efficiency of protein synthesis in mitochondria $[2,18,172,173]$. The absence of Afol in mitochondria of replicatively aging yeast elicits the following alterations in two signaling pathways of longevity regulation: (1) the anti-aging "back signaling" pathway is activated, thus enabling the Sfp1 protein to stimulate transcription of nuclear genes coding for protein components of cytoplasmic ribosomes [2,18,172]; and (2) the pro-aging TOR signaling pathway is inhibited, thus allowing to slow down the pro-aging process of protein synthesis in the cytosol and also to accelerate the anti-aging processes of autophagy, protein synthesis in mitochondria and transcription of many nuclear genes involved in cellular stress response [2,18,172] (Figure 2C).

Another group of mitochondrial processes that contribute to yeast replicative aging include the processing, stabilization and translational activation of mRNAs encoded by mtDNA; these processes are orchestrated by mitochondrial proteins constituting the so-called mitochondrial translation control (MTC) module [18,173-177] (Figure 2D). In the absence of any of these MTC proteins, the replicative aging of yeast is decelerated via the following two mechanisms: (1) the Pnc1- and Sir2-driven inhibition of the synthesis of extrachromosomal rDNA circles, one of the aging factors known to limit the replicative lifespan of the mother cell $[18,176]$; and (2) a decrease in the cellular concentration of cAMP and the ensuing attenuation of the cAMP-dependent protein kinase A (PKA) activity known to decelerate the anti-aging processes of autophagy and transcription of many stress-response genes in the nucleus as well as to accelerate the pro-aging process of protein synthesis in the cytosol $[18,137,173,176]$ (Figure 2D).

The maintenance of protein homeostasis (proteostasis) in mitochondria also contributes to the essential role of these organelles as signaling compartments in yeast replicative aging [2,18,20,178-180]. One of the mitochondrial protein components implicated in maintaining mitochondrial proteostasis is the m-AAA protease Afg3. It is actively involved in several proteostatic processes within the mitochondrial inner membrane-including degradation of misfolded proteins, assembly of several ETC protein complexes and processing of a protein component of the large subunit of the mitochondrial ribosome [178,179] (Figure 2E). These Afg3-driven proteostatic processes in mitochondria increase the rate of yeast replicative aging, likely because of their demonstrated ability to promote such pro-aging processes outside of mitochondria as protein synthesis in the cytosol and the accumulation of unfolded proteins in the ER [180].

Finally, it seems that the quantity of the Uth1 protein in the mitochondrial outer membrane is inversely proportional to the efficiency with which only dysfunctional mitochondria exhibiting the age-related traits of deteriorated functionality are degraded within vacuoles of replicatively aging yeast. Indeed, it has been shown that lack of Uth1 (1) impairs micromitophagy, an autophagic mode of non-selective vacuolar degradation of both functional and dysfunctional mitochondria; and (2) does not affect macromitophagy, an autophagic mode of selective vacuolar degradation of only dysfunctional mitochondria [181-183]. Importantly, lack of Uth1 also extends longevity of replicatively aging 
yeast [181-183]. Thus, Uth1 may function as a pro-aging protein factor on the surface of mitochondria; any intervention that reduces its abundance is therefore expected to delay replicative aging in yeast by concomitantly enhancing macromitophagic degradation of dysfunctional mitochondria and weakening micromitophagic degradation of functional mitochondria [18,182] (Figure 2F).

\subsection{Mechanisms by Which Mitochondrial Functionality Impacts Chronological Aging of Yeast}

A culture of chronologically aging yeast in a liquid medium progresses through a series of critical lifespan periods that define its longevity; we have recently proposed to use the term "lifespan checkpoint" (or simply "checkpoint") for describing each of these consecutive periods of yeast chronological lifespan [18-20,145,184]. The early-life checkpoints exist in logarithmic (L), diauxic (D) and post-diauxic (PD) growth phases; the late-life checkpoints take place in stationary (ST) phase of culturing $[19,20,184]$. Our concept of a "biomolecular network" posits that the rate and efficiency of progression through each of these lifespan checkpoints are monitored and/or modulated by a distinct set of checkpoint-specific "master regulator" proteins and protein complexes; a synergistic action of such master regulators defines longevity of chronologically aging yeast by orchestrating a stepwise development of a pro- or anti-aging cellular pattern [19,20,184]. A body of recent evidence supports the notion that different, age-related functional states of mitochondria define longevity of chronologically aging yeast by playing essential roles at several of the early-life and late-life checkpoints; we discuss this evidence below.

It seems that the earliest lifespan checkpoint defined by certain traits of mitochondrial functionality exists in L growth phase [19,20,145,155,184-188]; we call it "checkpoint 1". At checkpoint 1, the rapamycin-sensitive protein kinase Tor1 (a key component of the pro-aging TOR pathway) attenuates mitochondrial synthesis of oxidative phosphorylation (OXPHOS) enzymes that are encoded by mtDNA [185-188] (Figure 3). The extent of such attenuation (1) is modulated by variations in cellular energy status; and (2) establishes a certain rate of coupled mitochondrial respiration and a certain value of mitochondrial membrane potential; both these key traits of mitochondrial functionality define longevity of chronologically aging yeast cells - in part by influencing stress resistance of such cells $[19,20,145,155,185-188]$. The rate of coupled mitochondrial respiration and the value of mitochondrial membrane potential at checkpoint 1 are also modulated by caloric restriction, a longevity-extending dietary regimen whose impact on these characteristic traits of mitochondrial functionality at checkpoint 1 is mediated in part by its inhibitory effect on Tor1 [19,20,137,155,185-188].

Mitochondria, along with the pentose phosphate pathway, generate NADPH [189-191]. In mitochondria of chronologically "young" yeast cells, this primary source of cellular reducing equivalents is produced in two reactions of the TCA cycle as well as in reactions catalyzed by an acetaldehyde dehydrogenase and an NADH kinase [189-191]. NADPH drives reductive reactions of the biosynthetic pathways for amino acids, fatty acids and sterols [189-191]; moreover, NADPH is also an electron donor for thioredoxin and glutathione reductase systems that maintain cellular redox homeostasis $[189,191]$. At lifespan checkpoint 2, which exists in D and PD growth phases, these two enzymatic systems play essential roles in delaying yeast chronological aging because they both reduce the extent of oxidative damage to many thiol-containing proteins in the mitochondria, nucleus and cytosol [19,20,191] (Figure 3). 


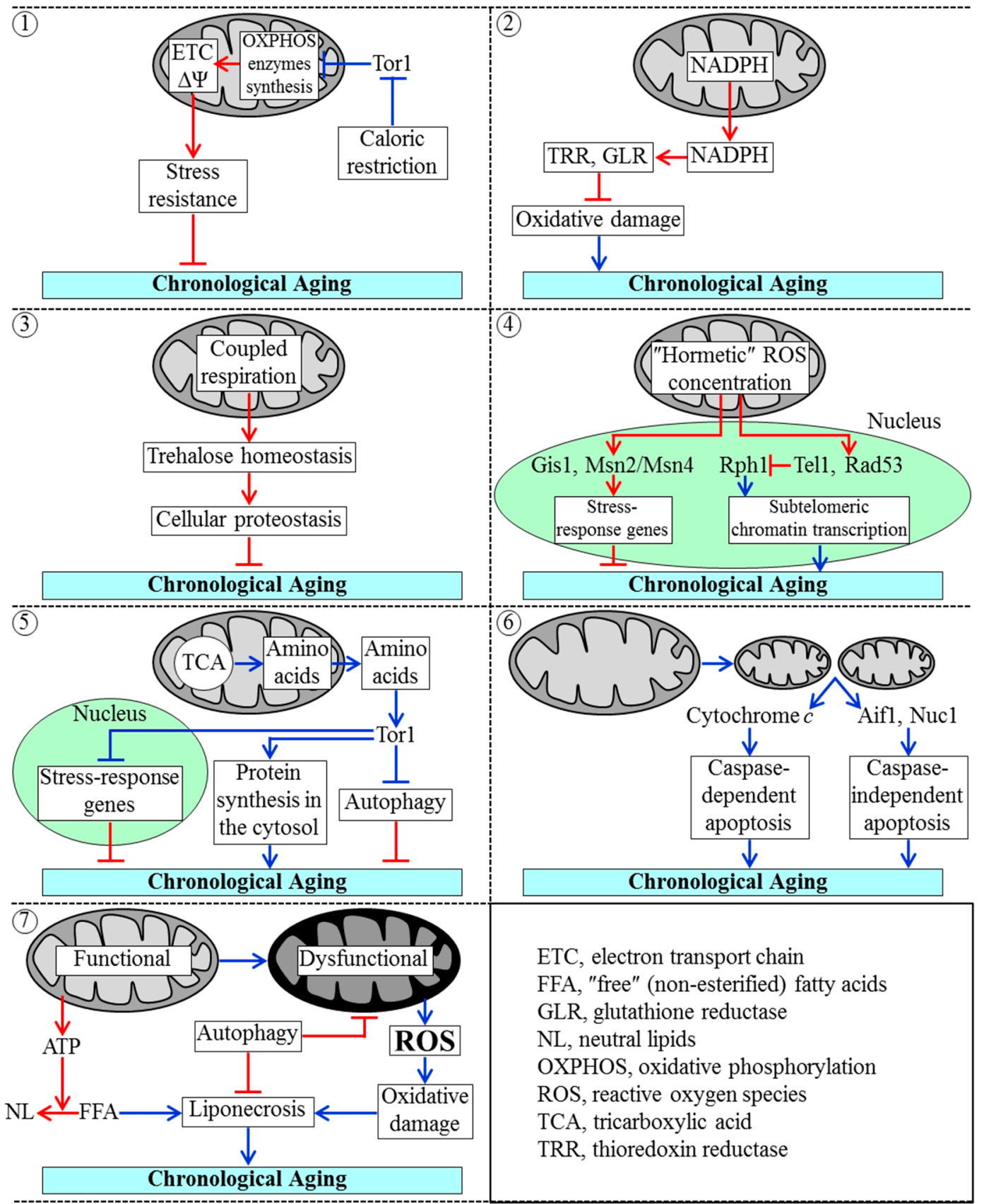

Figure 3. A chronologically aging culture of yeast cells progresses through at least seven consecutive "checkpoints", each of which defines yeast longevity. Checkpoint 1: The protein kinase Tor1 mitigates the synthesis of mitochondrial DNA-encoded enzymes of the oxidative phosphorylation (OXPHOS) system in mitochondria, thereby allowing to set up a certain rate of electron flow through the mitochondrial electron transport chain (ETC) and a certain value of mitochondrial membrane potential $(\Delta \Psi)$. These two traits of mitochondrial functionality establish a magnitude of cell resistance to stresses and, thus, define the chronological lifespan of yeast. Caloric restriction extends yeast chronological lifespan by suppressing Tor1; Checkpoint 2: Mitochondria-generated NADPH is an electron donor for thioredoxin and glutathione reductase (TRR and GLR, respectively) systems outside of mitochondria. Both these systems delay yeast chronological aging by reducing the degree of oxidative damage to many proteins in various cellular locations; Checkpoint 3: The 
efficiency of coupled mitochondrial respiration defines the cellular concentration of trehalose, which in chronologically "young" yeast cells acts as a longevity-extending metabolite by enhancing cellular proteostasis; Checkpoint 4: If mitochondria-generated reactive oxygen species (ROS) in chronologically "young" yeast cells are maintained at a "hormetic" level, ROS extend chronological lifespan by: (1) activating the transcription factors Gis1, Msn2 and Msn4, which promote expression of many longevity-extending nuclear genes; and (2) stimulating the longevity-extending Tel1-Rad53-Rph1 signaling pathway, which reduces the extent of damage to telomeric DNA in the nucleus; Checkpoint 5: Amino acids that are synthesized in and released from mitochondria activate the TOR signaling pathway; this pathway accelerates chronological aging by simulating protein synthesis in the cytosol, attenuating transcription of many stress-response genes in the nucleus, and suppressing autophagy of dysfunctional organelles and macromolecules; Checkpoint 6: A release of cytochrome $c$, Aifl and Nuc1 from fragmented mitochondria in chronologically "old" yeast cells stimulates caspase-dependent and caspase-independent modes of apoptotic cell death, thus limiting yeast chronological lifespan; Checkpoint 7: Yeast chronological lifespan is shortened by "liponecrosis", a mode of cell death that in chronologically "old" yeast cells is triggered due to (1) a reduced ability of mitochondria to generate ATP for the incorporation of non-esterified ("free") fatty acids (FFA) into neutral lipids (NL); (2) a decline in the efficiency of an autophagic degradation of aged and dysfunctional mitochondria; and (3) a rise in the efficiencies with which mitochondria generate and release ROS. Activation arrows and inhibition bars denote pro-aging processes (displayed in blue color) or anti-aging processes (displayed in red color). See the text for additional details.

The rate of coupled mitochondrial respiration in yeast cells progressing through $\mathrm{D}$ and PD growth phases defines their chronological lifespan in part by modulating cellular concentration of trehalose [19,20,145,188,192]. A lifespan checkpoint at which coupled mitochondrial respiration is linked to the maintenance of cellular trehalose homeostasis is called checkpoint 3 [19,20] (Figure 3). Trehalose is a non-reducing disaccharide that controls cellular proteostasis (i.e., a dynamic balance between protein folding, misfolding, unfolding, refolding, oxidative damage, solubility and aggregation) throughout lifespan of chronologically aging yeast $[19,192]$.

A distinct lifespan checkpoint, which we call checkpoint 4, is defined by the concentration of ROS produced by and released from mitochondria in chronologically "young" yeast cells; this checkpoint exists in D and PD growth phases [19,20,139,140,145,193-195]. If the concentration of mitochondria-derived ROS in such cells is maintained at a hormetic level, these ROS act as signaling molecules that extend yeast longevity by: (1) stimulating the transcription factors Gis1, Msn2 and Msn4, which respond by activating expression of many nuclear genes known for their essential longevity-extending roles in nutrient sensing, carbohydrate metabolism, stress resistance and survival [140,194-197]; and (2) triggering the anti-aging Tel1-Rad53-Rph1 signaling pathway, which in response reduces the extent of damage to telomeric DNA by attenuating transcription of subtelomeric chromatin regions in the nucleus [140,194,195] (Figure 3). 
The abilities of mitochondria to convert some of the intermediates of the TCA cycle into amino acids and to release these amino acids [189,190,198] define lifespan checkpoint 5, which exists in D and PD growth phases $[18,19]$. Following their release from mitochondria, neutral amino acids stimulate protein kinase Tor1; the ensuing activation of the pro-aging TOR signaling pathway accelerates chronological aging by promoting protein synthesis in the cytosol, attenuating protein synthesis in mitochondria, slowing down transcription of many nuclear genes involved in stress response, and hindering autophagic degradation of dysfunctional organelles and macromolecules [18,19,185,186,198-203] (Figure 3). Transcription of stress-response genes in the nucleus and autophagy in the cytoplasm are also attenuated by the pro-aging cAMP/PKA (cAMP/protein kinase A) signaling pathway, which overlaps with the TOR pathway [18,19,137,154,201,203].

The fragmentation of a tubular mitochondrial network into individual mitochondria and the efflux of some proteins (including cytochrome $c$ as well as the "moonlighting" endonucleases Aif1 and Nuc1) from the fragmented mitochondria take place in chronologically "old" yeast cells that enter ST growth phase; these characteristic changes in mitochondrial morphology limit yeast chronological lifespan by eliciting the caspase-dependent and caspase-independent pathways of apoptotic programmed cell death (PCD) $[19,145,155,204-209]$. A lifespan checkpoint at which such age-related changes in mitochondrial morphology are linked to age-related forms of mitochondria-controlled apoptotic PCD exists in ST growth phase; we call it checkpoint 6 [19,20,145] (Figure 3).

A lifespan checkpoint at which several distinct traits of mitochondrial functionality and homeostasis are linked to an age-related "liponecrotic" form of PCD is called checkpoint 7; it exists in ST growth phase $[19,20,210,211]$. These traits include (1) the efficiency with which mitochondria generate energy needed for the detoxification of non-esterified fatty acids through their incorporation into neutral lipids; an age-related decline in such efficiency accelerates age-related liponecrotic PCD by causing the excessive accumulation of monounsaturated fatty acids in cellular membranes; (2) the efficiencies with which mitochondria produce and release ROS; an age-related rise in such efficiencies above a threshold accelerates age-related liponecrotic PCD by causing oxidative damage to cellular macromolecules and organelles; and (3) the efficiency with which aged and dysfunctional mitochondria undergo an Atg32and Aup1-driven selective autophagic degradation; an age-related decline in such efficiency accelerates age-related liponecrotic PCD by impairing the maintenance of a healthy population of fully functional mitochondria [18-20,158,159,182,210-215] (Figure 3).

Some traits of mitochondrial functionality have not been linked to a particular lifespan checkpoint yet and may be associated with more than one of such checkpoints in chronologically aging yeast. One of these traits is the maintenance of mitochondrial genome integrity and copy number; the essential role of this trait in defining the rate of chronological aging depends on the mitochondrial base-excision repair enzyme Ntg1 [195]. It seems conceivable that an aging-associated mitigation of the Ntg1-governed pathway for maintaining mitochondrial genome integrity and copy number may underlie such longevity-shortening process observed in chronologically aging yeast as an age-related rise in the rates of mtDNA fragments migration to the nucleus and in their insertion into nuclear DNA [216,217]. The ensuing reduction of nuclear genome stability is an important contributing factor to chronological aging in yeast [18,19,195,216,217]. Of note, the Ntg1-governed pathway: (1) overlaps with a branch of the pro-aging TOR signaling pathway which at checkpoint 1 operates in attenuating mitochondrial synthesis of mtDNA-encoded OXPHOS enzymes; (2) modulates the anti-aging Tel1-Rad53-Rph1 signaling 
pathway which at checkpoint 4 responses to hormetic concentrations of mitochondria-generated ROS by decreasing the extent of damage to telomeric DNA [140,194,195] (Figure 3). These observations further support the notion that the Ntg1-dependent maintenance of mitochondrial genome integrity and copy number is a trait of mitochondrial functionality that may be associated with more than one of the lifespan checkpoints in chronologically aging yeast.

Another trait of mitochondrial functionality that may define more than one of the lifespan checkpoints in chronologically aging yeast is the lipid compositions of both mitochondrial membranes. Indeed, lithocholic bile acid (LCA) extends yeast chronological lifespan by eliciting an age-related remodeling of mitochondrial membrane lipidome $[139,193,218]$. Such remodeling is likely to be responsible for the age-related changes in mitochondrial size, number and morphology observed in chronologically aging yeast cells exposed to LCA, as well as for LCA-driven alterations in the age-related dynamics of mitochondrial respiration, membrane potential, ATP synthesis and ROS homeostasis seen in these cells $[139,193,218]$. Our recent data suggest that these characteristic changes in mitochondrial membrane lipidome and functionality elicited by LCA in chronologically aging yeast cells enable mitochondria to operate as signaling organelles that modulate activities of several transcription factors linked to some of the above lifespan checkpoints; these factors respond by altering transcription of many longevity-defining nuclear genes, thus establishing an anti-aging transcriptional program [219].

\section{Conclusions and Future Perspectives}

Studies of the yeast $S$. cerevisiae have revealed that mitochondria function as signaling organelles orchestrating many longevity-defining processes in other cellular compartments, thus establishing the rate of cellular aging. The molecular and cellular mechanisms by which various traits of mitochondrial functionality define longevity of replicatively and chronologically aging yeast have emerged. These mechanisms have been characterized separately for the replicative and chronological paradigms of yeast aging. These two paradigms are traditionally investigated under controllable laboratory conditions independently from each other by measuring two different aspects of the aging process in yeast. However, emergent evidence strongly suggests that the replicative and chronological modes of yeast aging are interconnected and may converge into a single aging process; for a recent review of this topic, see reference [20]. Therefore, the major challenge now is to understand how the longevity-defining traits of mitochondrial functionality and signaling pathways modulated by these traits in replicatively aging yeast influence longevity-defining cellular processes in chronologically aging yeast; and vice versa, how the longevity-defining mitochondrial functions and signaling pathways they control in chronologically aging yeast impact longevity-defining cellular processes in replicatively aging yeast.

\section{Acknowledgments}

We are grateful to current and former members of the Titorenko laboratory for discussions. This research was supported by grants from the NSERC of Canada and Concordia University Chair Fund to Vladimir I. Titorenko. Adam Beach was supported by a Frederick Banting and Charles Best Doctoral Scholarship Award from the Canadian Institutes of Health Research. Veronika Svistkova was supported by an Undergraduate Summer Award from the NSERC of Canada. Vladimir I. Titorenko is a Concordia University Research Chair in Genomics, Cell Biology and Aging. 


\section{Conflicts of Interest}

The authors declare no conflict of interest.

\section{References}

1. McBride, H.M.; Neuspiel, M.; Wasiak, S. Mitochondria: More than just a powerhouse. Curr. Biol. 2006, 16, R551-R560.

2. Breitenbach, M.; Laun, P.; Dickinson, J.R.; Klocker, A.; Rinnerthaler, M.; Dawes, I.W.; Aung-Htut, M.T.; Breitenbach-Koller, L.; Caballero, A.; Nyström, T.; et al. The role of mitochondria in the aging processes of yeast. Subcell. Biochem. 2012, 57, 55-78.

3. Nunnari, J.; Suomalainen, A. Mitochondria: In sickness and in health. Cell 2012, 148, 1145-1159.

4. Vafai, S.B.; Mootha, V.K. Mitochondrial disorders as windows into an ancient organelle. Nature 2012, 491, 374-383.

5. Pagliarini, D.J.; Rutter, J. Hallmarks of a new era in mitochondrial biochemistry. Genes Dev. 2013, 27, 2615-2627.

6. Lane, N. Power, Sex, Suicide: Mitochondria and the Meaning of Life; Oxford University Press: New York, NY, USA, 2006; p. 368.

7. Hill, B.G.; Benavides, G.A.; Lancaster, J.R., Jr.; Ballinger, S.; Dell’Italia, L.; Jianhua, Z.; Darley-Usmar, V.M. Integration of cellular bioenergetics with mitochondrial quality control and autophagy. Biol. Chem. 2012, 393, 1485-1512.

8. Huang, H.; Frohman, M.A. Lipid signaling on the mitochondrial surface. Biochim. Biophys. Acta 2009, 1791, 839-844.

9. Westermann, B. Mitochondrial fusion and fission in cell life and death. Nat. Rev. Mol. Cell Biol. 2010, 11, 872-884.

10. Green, D.R.; Galluzzi, L.; Kroemer, G. Mitochondria and the autophagy-inflammation-cell death axis in organismal aging. Science 2011, 333, 1109-1112.

11. Collins, Y.; Chouchani, E.T.; James, A.M.; Menger, K.E.; Cochemé, H.M.; Murphy, M.P. Mitochondrial redox signalling at a glance. J. Cell Sci. 2012, 125, 801-806.

12. Galluzzi, L.; Kepp, O.; Kroemer, G. Mitochondria: Master regulators of danger signalling. Nat. Rev. Mol. Cell Biol. 2012, 13, 780-788.

13. Galluzzi, L.; Kepp, O.; Trojel-Hansen, C.; Kroemer, G. Non-apoptotic functions of apoptosis-regulatory proteins. EMBO Rep. 2012, 13, 322-330.

14. Gao, Q.; Frohman, M.A. Roles for the lipid-signaling enzyme MitoPLD in mitochondrial dynamics, piRNA biogenesis, and spermatogenesis. BMB Rep. 2012, 45, 7-13.

15. Perier, C.; Vila, M. Mitochondrial biology and Parkinson's disease. Cold Spring Harb. Perspect. Med. 2012, 2, doi:10.1101/cshperspect.a009332.

16. Tait, S.W.; Green, D.R. Mitochondria and cell signalling. J. Cell Sci. 2012, 125, 807-815.

17. Andersen, J.L.; Kornbluth, S. The tangled circuitry of metabolism and apoptosis. Mol. Cell 2013, 49, 399-410.

18. Leonov, A.; Titorenko, V.I. A network of interorganellar communications underlies cellular aging. IUBMB Life 2013, 65, 665-674. 
19. Arlia-Ciommo, A.; Leonov, A.; Piano, A.; Svistkova, V.; Titorenko, V.I. Cell-autonomous mechanisms of chronological aging in the yeast Saccharomyces cerevisiae. Microb. Cell 2014, 1, $164-178$.

20. Arlia-Ciommo, A.; Piano, A.; Leonov, A.; Svistkova, V.; Titorenko, V.I. Quasi-programmed aging of budding yeast: A trade-off between programmed processes of cell proliferation, differentiation, stress response, survival and death defines yeast lifespan. Cell Cycle 2014, 13, 3336-3349.

21. Chandel, N.S. Mitochondria as signaling organelles. BMC Biol. 2014, 12, doi:10.1186/1741-7007-12-34.

22. Friedman, J.R.; Nunnari, J. Mitochondrial form and function. Nature 2014, 505, 335-343.

23. Green, D.R.; Galluzzi, L.; Kroemer, G. Cell biology. Metabolic control of cell death. Science 2014, 345, doi:10.1126/science. 1250256.

24. Kasahara, A.; Scorrano, L. Mitochondria: From cell death executioners to regulators of cell differentiation. Trends Cell Biol. 2014, 24, 761-770.

25. Kaufman, R.J.; Malhotra, J.D. Calcium trafficking integrates endoplasmic reticulum function with mitochondrial bioenergetics. Biochim. Biophys. Acta 2014, 1843, 2233-2239.

26. Labbé, K.; Murley, A.; Nunnari, J. Determinants and functions of mitochondrial behavior. Annu. Rev. Cell Dev. Biol. 2014, 30, 357-391.

27. Naon, D.; Scorrano, L. At the right distance: ER-mitochondria juxtaposition in cell life and death. Biochim. Biophys. Acta 2014, 1843, 2184-2194.

28. Van Vliet, A.R.; Verfaillie, T.; Agostinis, P. New functions of mitochondria associated membranes in cellular signaling. Biochim. Biophys. Acta 2014, 1843, 2253-2262.

29. Finley, L.W.; Haigis, M.C. The coordination of nuclear and mitochondrial communication during aging and calorie restriction. Ageing Res. Rev. 2009, 8, 173-188.

30. Anderson, K.A.; Hirschey, M.D. Mitochondrial protein acetylation regulates metabolism. Essays Biochem. 2012, 52, 23-35.

31. He, W.; Newman, J.C.; Wang, M.Z.; Ho, L.; Verdin, E. Mitochondrial sirtuins: Regulators of protein acylation and metabolism. Trends Endocrinol. Metab. 2012, 23, 467-476.

32. Sack, M.N.; Finkel, T. Mitochondrial metabolism, sirtuins, and aging. Cold Spring Harb. Perspect. Biol. 2012, 4, doi:10.1101/cshperspect.a013102.

33. Wellen, K.E.; Thompson, C.B. A two-way street: Reciprocal regulation of metabolism and signalling. Nat. Rev. Mol. Cell Biol. 2012, 13, 270-276.

34. Andreux, P.A.; Houtkooper, R.H.; Auwerx, J. Pharmacological approaches to restore mitochondrial function. Nat. Rev. Drug Discov. 2013, 12, 465-483.

35. Kaelin, W.G., Jr.; McKnight, S.L. Influence of metabolism on epigenetics and disease. Cell 2013, 153, 56-69.

36. Burkewitz, K.; Zhang, Y.; Mair, W.B. AMPK at the nexus of energetics and aging. Cell Metab. 2014, 20, 10-25.

37. Cerutti, R.; Pirinen, E.; Lamperti, C.; Marchet, S.; Sauve, A.A.; Li, W.; Leoni, V.; Schon, E.A.; Dantzer, F.; Auwerx, J.; et al. NAD ${ }^{+}$-dependent activation of Sirtl corrects the phenotype in a mouse model of mitochondrial disease. Cell Metab. 2014, 19, 1042-1049. 
38. Eisenberg, T.; Schroeder, S.; Andryushkova, A.; Pendl, T.; Küttner, V.; Bhukel, A.; Mariño, G.; Pietrocola, F.; Harger, A.; Zimmermann, A.; et al. Nucleocytosolic depletion of the energy metabolite acetyl-coenzyme A stimulates autophagy and prolongs lifespan. Cell Metab. 2014, 19, 431-444.

39. Giorgio, M.; Trinei, M.; Migliaccio, E.; Pelicci, P.G. Hydrogen peroxide: A metabolic by-product or a common mediator of ageing signals? Nat. Rev. Mol. Cell Biol. 2007, 8, 722-728.

40. Dai, D.F.; Chiao, Y.A.; Marcinek, D.J.; Szeto, H.H.; Rabinovitch, P.S. Mitochondrial oxidative stress in aging and healthspan. Longev. Healthspan 2014, 3, doi:10.1186/2046-2395-3-6.

41. Stuart, J.A.; Maddalena, L.A.; Merilovich, M.; Robb, E.L. A midlife crisis for the mitochondrial free radical theory of aging. Longev. Healthspan 2014, 3, doi:10.1186/2046-2395-3-4.

42. Sena, L.A.; Chandel, N.S. Physiological roles of mitochondrial reactive oxygen species. Mol. Cell 2012, 48, 158-167.

43. Schieber, M.; Chandel, N.S. ROS function in redox signaling and oxidative stress. Curr. Biol. 2014, 24, R453-R462.

44. Hekimi, S.; Lapointe, J.; Wen, Y. Taking a "good" look at free radicals in the aging process. Trends Cell Biol. 2011, 21, 569-576.

45. Ray, P.D.; Huang, B.W.; Tsuji, Y. Reactive oxygen species (ROS) homeostasis and redox regulation in cellular signaling. Cell Signal. 2012, 24, 981-990.

46. Kawagishi, H.; Finkel, T. Unraveling the truth about antioxidants: ROS and disease: Finding the right balance. Nat. Med. 2014, 20, 711-713.

47. Ristow, M. Unraveling the truth about antioxidants: Mitohormesis explains ROS-induced health benefits. Nat. Med. 2014, 20, 709-711.

48. Schroeder, E.A.; Shadel, G.S. Alternative mitochondrial fuel extends life span. Cell Metab. 2012, 15, 417-418.

49. Hwang, A.B.; Ryu, E.A.; Artan, M.; Chang, H.W.; Kabir, M.H.; Nam, H.J.; Lee, D.; Yang, J.S.; Kim, S.; Mair, W.B.; et al. Feedback regulation via AMPK and HIF-1 mediates ROS-dependent longevity in Caenorhabditis elegans. Proc. Natl. Acad. Sci. USA 2014, 111, E4458-E4467.

50. Schieber, M.; Chandel, N.S. TOR signaling couples oxygen sensing to lifespan in C. elegans. Cell Rep. 2014, 9, 9-15.

51. Xu, S.; Chisholm, A.D. C. elegans epidermal wounding induces a mitochondrial ROS burst that promotes wound repair. Dev. Cell 2014, 31, 48-60.

52. Yee, C.; Yang, W.; Hekimi, S. The intrinsic apoptosis pathway mediates the pro-longevity response to mitochondrial ROS in C. elegans. Cell 2014, 157, 897-909.

53. Yun, J.; Finkel, T. Mitohormesis. Cell Metab. 2014, 19, 757-766.

54. Lill, R.; Mühlenhoff, U. Maturation of iron-sulfur proteins in eukaryotes: Mechanisms, connected processes, and diseases. Annu. Rev. Biochem. 2008, 77, 669-700.

55. Sheftel, A.; Stehling, O.; Lill, R. Iron-sulfur proteins in health and disease. Trends Endocrinol. Metab. 2010, 21, 302-314.

56. Xu, X.M.; Møller, S.G. Iron-sulfur clusters: Biogenesis, molecular mechanisms, and their functional significance. Antioxid. Redox Signal. 2011, 15, 271-307. 
57. Lill, R.; Hoffmann, B.; Molik, S.; Pierik, A.J.; Rietzschel, N.; Stehling, O.; Uzarska, M.A.; Webert, H.; Wilbrecht, C.; Mühlenhoff, U. The role of mitochondria in cellular iron-sulfur protein biogenesis and iron metabolism. Biochim. Biophys. Acta 2012, 1823, 1491-1508.

58. Beilschmidt, L.K.; Puccio, H.M. Mammalian Fe-S cluster biogenesis and its implication in disease. Biochimie 2014, 100, 48-60.

59. Stehling, O.; Wilbrecht, C.; Lill, R. Mitochondrial iron-sulfur protein biogenesis and human disease. Biochimie 2014, 100, 61-77.

60. Veatch, J.R.; McMurray, M.A.; Nelson, Z.W.; Gottschling, D.E. Mitochondrial dysfunction leads to nuclear genome instability via an iron-sulfur cluster defect. Cell 2009, 137, 1247-1258.

61. Gari, K.; León Ortiz, A.M.; Borel, V.; Flynn, H.; Skehel, J.M.; Boulton, S.J. MMS19 links cytoplasmic iron-sulfur cluster assembly to DNA metabolism. Science 2012, 337, 243-245.

62. Gottschling, D.E. Molecular biology. Fragile delivery to the genome. Science 2012, 337, 160-161.

63. Stehling, O.; Vashisht, A.A.; Mascarenhas, J.; Jonsson, Z.O.; Sharma, T.; Netz, D.J.; Pierik, A.J.; Wohlschlegel, J.A.; Lill, R. MMS19 assembles iron-sulfur proteins required for DNA metabolism and genomic integrity. Science 2012, 337, 195-199.

64. Haynes, C.M.; Ron, D. The mitochondrial UPR — Protecting organelle protein homeostasis. J. Cell Sci. 2010, 123, 3849-3855.

65. Haynes, C.M.; Yang, Y.; Blais, S.P.; Neubert, T.A.; Ron, D. The matrix peptide exporter HAF-1 signals a mitochondrial UPR by activating the transcription factor ZC376.7 in C. elegans. Mol. Cell 2010, 37, 529-540.

66. Kirstein-Miles, J.; Morimoto, R.I. Peptides signal mitochondrial stress. Cell Metab. 2010, 11, 177-178.

67. Baker, B.M.; Haynes, C.M. Mitochondrial protein quality control during biogenesis and aging. Trends Biochem. Sci. 2011, 36, 254-261.

68. Nargund, A.M.; Pellegrino, M.W.; Fiorese, C.J.; Baker, B.M.; Haynes, C.M. Mitochondrial import efficiency of ATFS-1 regulates mitochondrial UPR activation. Science 2012, 337, 587-590.

69. Vögtle, F.N.; Meisinger, C. Sensing mitochondrial homeostasis: The protein import machinery takes control. Dev. Cell 2012, 23, 234-236.

70. Haynes, C.M.; Fiorese, C.J.; Lin, Y.F. Evaluating and responding to mitochondrial dysfunction: The mitochondrial unfolded-protein response and beyond. Trends Cell Biol. 2013, 23, 311-318.

71. Pellegrino, M.W.; Nargund, A.M.; Haynes, C.M. Signaling the mitochondrial unfolded protein response. Biochim. Biophys. Acta 2013, 1833, 410-416.

72. Hill, S.; van Remmen, H. Mitochondrial stress signaling in longevity: A new role for mitochondrial function in aging. Redox Biol. 2014, 2, 936-944.

73. Mottis, A.; Jovaisaite, V.; Auwerx, J. The mitochondrial unfolded protein response in mammalian physiology. Mamm. Genome 2014, 25, 424-433.

74. Hashimoto, Y.; Niikura, T.; Tajima, H.; Yasukawa, T.; Sudo, H.; Ito, Y.; Kita, Y.; Kawasumi, M.; Kouyama, K.; Doyu, M.; et al. A rescue factor abolishing neuronal cell death by a wide spectrum of familial Alzheimer's disease genes and A $\beta$. Proc. Natl. Acad. Sci. USA 2001, 98, 6336-6341.

75. Tajima, H.; Niikura, T.; Hashimoto, Y.; Ito, Y.; Kita, Y.; Terashita, K.; Yamazaki, K.; Koto, A.; Aiso, S.; Nishimoto, I. Evidence for in vivo production of Humanin peptide, a neuroprotective factor against Alzheimer's disease-related insults. Neurosci. Lett. 2002, 324, 227-231. 
76. Guo, B.; Zhai, D.; Cabezas, E.; Welsh, K.; Nouraini, S.; Satterthwait, A.C.; Reed, J.C. Humanin peptide suppresses apoptosis by interfering with Bax activation. Nature 2003, 423, 456-461.

77. Ikonen, M.; Liu, B.; Hashimoto, Y.; Ma, L.; Lee, K.W.; Niikura, T.; Nishimoto, I.; Cohen, P. Interaction between the Alzheimer's survival peptide humanin and insulin-like growth factor-binding protein 3 regulates cell survival and apoptosis. Proc. Natl. Acad. Sci. USA 2003, 100, 13042-13047.

78. Harada, M.; Habata, Y.; Hosoya, M.; Nishi, K.; Fujii, R.; Kobayashi, M.; Hinuma, S. N-formylated humanin activates both formyl peptide receptor-like 1 and 2. Biochem. Biophys. Res. Commun. 2004, 324, 255-261.

79. Zhai, D.; Luciano, F.; Zhu, X.; Guo, B.; Satterthwait, A.C.; Reed, J.C. Humanin binds and nullifies Bid activity by blocking its activation of Bax and Bak. J. Biol. Chem. 2005, 280, 15815-15824.

80. Lee, C.; Yen, K.; Cohen, P. Humanin: A harbinger of mitochondrial-derived peptides? Trends Endocrinol. Metab. 2013, 24, 222-228.

81. Yen, K.; Lee, C.; Mehta, H.; Cohen, P. The emerging role of the mitochondrial-derived peptide humanin in stress resistance. J. Mol. Endocrinol. 2013, 50, R11-R19.

82. Rabiet, M.J.; Huet, E.; Boulay, F. Human mitochondria-derived $N$-formylated peptides are novel agonists equally active on FPR and FPRL1, while Listeria monocytogenes-derived peptides preferentially activate FPR. Eur. J. Immunol. 2005, 35, 2486-2495.

83. Hauser, C.J.; Sursal, T.; Rodriguez, E.K.; Appleton, P.T.; Zhang, Q.; Itagaki, K. Mitochondrial damage associated molecular patterns from femoral reamings activate neutrophils through formyl peptide receptors and P44/42 MAP kinase. J. Orthop. Trauma 2010, 24, 534-538.

84. Raoof, M.; Zhang, Q.; Itagaki, K.; Hauser, C.J. Mitochondrial peptides are potent immune activators that activate human neutrophils via FPR-1. J. Trauma 2010, 68, 1328-1332.

85. Zhang, Q.; Raoof, M.; Chen, Y.; Sumi, Y.; Sursal, T.; Junger, W.; Brohi, K.; Itagaki, K.; Hauser, C.J. Circulating mitochondrial DAMPs cause inflammatory responses to injury. Nature 2010, 464, 104-107.

86. Nakahira, K.; Haspel, J.A.; Rathinam, V.A.; Lee, S.J.; Dolinay, T.; Lam, H.C.; Englert, J.A.; Rabinovitch, M.; Cernadas, M.; Kim, H.P.; et al. Autophagy proteins regulate innate immune responses by inhibiting the release of mitochondrial DNA mediated by the NALP3 inflammasome. Nat. Immunol. 2011, 12, 222-230.

87. Tschopp, J. Mitochondria: Sovereign of inflammation? Eur. J. Immunol. 2011, 41, 1196-1202.

88. Mathew, A.; Lindsley, T.A.; Sheridan, A.; Bhoiwala, D.L.; Hushmendy, S.F.; Yager, E.J.; Ruggiero, E.A.; Crawford, D.R. Degraded mitochondrial DNA is a newly identified subtype of the damage associated molecular pattern (DAMP) family and possible trigger of neurodegeneration. J. Alzheimers Dis. 2012, 30, 617-627.

89. Sun, S.; Sursal, T.; Adibnia, Y.; Zhao, C.; Zheng, Y.; Li, H.; Otterbein, L.E.; Hauser, C.J.; Itagaki, K. Mitochondrial DAMPs increase endothelial permeability through neutrophil dependent and independent pathways. PLoS One 2013, 8, e59989.

90. Sutendra, G.; Kinnaird, A.; Dromparis, P.; Paulin, R.; Stenson, T.H.; Haromy, A.; Hashimoto, K.; Zhang, N.; Flaim, E.; Michelakis, E.D. A nuclear pyruvate dehydrogenase complex is important for the generation of acetyl-CoA and histone acetylation. Cell 2014, 158, 84-97. 
91. Durieux, J.; Wolff, S.; Dillin, A. The cell-non-autonomous nature of electron transport chain-mediated longevity. Cell 2011, 144, 79-91.

92. Taylor, R.C.; Berendzen, K.M.; Dillin, A. Systemic stress signalling: Understanding the cell non-autonomous control of proteostasis. Nat. Rev. Mol. Cell Biol. 2014, 15, 211-217.

93. Esseltine, J.L.; Scott, J.D. AKAP signaling complexes: Pointing towards the next generation of therapeutic targets? Trends Pharmacol. Sci. 2013, 34, 648-655.

94. Koshiba, T. Mitochondrial-mediated antiviral immunity. Biochim. Biophys. Acta 2013, 1833, 225-232.

95. Taylor, S.S.; Zhang, P.; Steichen, J.M.; Keshwani, M.M.; Kornev, A.P. PKA: Lessons learned after twenty years. Biochim. Biophys. Acta 2013, 1834, 1271-1278.

96. Giménez-Cassina, A.; Garcia-Haro, L.; Choi, C.S.; Osundiji, M.A.; Lane, E.A.; Huang, H.; Yildirim, M.A.; Szlyk, B.; Fisher, J.K.; Polak, K.; et al. Regulation of hepatic energy metabolism and gluconeogenesis by BAD. Cell Metab. 2014, 19, 272-284.

97. Liu, L.; Sakakibara, K.; Chen, Q.; Okamoto, K. Receptor-mediated mitophagy in yeast and mammalian systems. Cell Res. 2014, 24, 787-795.

98. Pourcelot, M.; Arnoult, D. Mitochondrial dynamics and the innate antiviral immune response. FEBS J. 2014, 281, 3791-3802.

99. Westermann, B. Mitochondrial inheritance in yeast. Biochim. Biophys. Acta 2014, 1837, 1039-1046.

100. Rowland, A.A.; Voeltz, G.K. Endoplasmic reticulum-mitochondria contacts: Function of the junction. Nat. Rev. Mol. Cell Biol. 2012, 13, 607-625.

101. Helle, S.C.; Kanfer, G.; Kolar, K.; Lang, A.; Michel, A.H.; Kornmann, B. Organization and function of membrane contact sites. Biochim. Biophys. Acta 2013, 1833, 2526-2541.

102. Kornmann, B. The molecular hug between the ER and the mitochondria. Curr. Opin. Cell Biol. 2013, 25, 443-448.

103. Daniele, T.; Schiaffino, M.V. Organelle biogenesis and interorganellar connections: Better in contact than in isolation. Commun. Integr. Biol. 2014, 7, doi:10.4161/cib.29587.

104. Elbaz-Alon, Y.; Rosenfeld-Gur, E.; Shinder, V.; Futerman, A.H.; Geiger, T.; Schuldiner, M. A dynamic interface between vacuoles and mitochondria in yeast. Dev. Cell 2014, 30, 95-102.

105. Hönscher, C.; Mari, M.; Auffarth, K.; Bohnert, M.; Griffith, J.; Geerts, W.; van der Laan, M.; Cabrera, M.; Reggiori, F.; Ungermann, C. Cellular metabolism regulates contact sites between vacuoles and mitochondria. Dev. Cell 2014, 30, 86-94.

106. Klecker, T.; Böckler, S.; Westermann, B. Making connections: Interorganelle contacts orchestrate mitochondrial behavior. Trends Cell Biol. 2014, 24, 537-545.

107. Marchi, S.; Patergnani, S.; Pinton, P. The endoplasmic reticulum-mitochondria connection: One touch, multiple functions. Biochim. Biophys. Acta 2014, 1837, 461-469.

108. Prinz, WA. Bridging the gap: Membrane contact sites in signaling, metabolism, and organelle dynamics. J. Cell Biol. 2014, 205, 759-769.

109. Van der Laan, M.; Bohnert, M.; Wiedemann, N.; Pfanner, N. Role of MINOS in mitochondrial membrane architecture and biogenesis. Trends Cell Biol. 2012, 22, 185-192. 
110. Hamasaki, M.; Furuta, N.; Matsuda, A.; Nezu, A.; Yamamoto, A.; Fujita, N.; Oomori, H.; Noda, T.; Haraguchi, T.; Hiraoka, Y.; et al. Autophagosomes form at ER-mitochondria contact sites. Nature 2013, 495, 389-393.

111. Böckler, S.; Westermann, B. Mitochondrial ER contacts are crucial for mitophagy in yeast. Dev. Cell 2014, 28, 450-458.

112. Lahiri, S.; Chao, J.T.; Tavassoli, S.; Wong, A.K.; Choudhary, V.; Young, B.P.; Loewen, C.J.; Prinz, W.A. A conserved endoplasmic reticulum membrane protein complex (EMC) facilitates phospholipid transfer from the ER to mitochondria. PLoS Biol. 2014, 12, e1001969.

113. Schlattner, U.; Tokarska-Schlattner, M.; Rousseau, D.; Boissan, M.; Mannella, C.; Epand, R.; Lacombe, M.L. Mitochondrial cardiolipin/phospholipid trafficking: The role of membrane contact site complexes and lipid transfer proteins. Chem. Phys. Lipids 2014, 179, 32-41.

114. Tamura, Y.; Sesaki, H.; Endo, T. Phospholipid transport via mitochondria. Traffic 2014, 15, 933-945.

115. Tatsuta, T.; Scharwey, M.; Langer, T. Mitochondrial lipid trafficking. Trends Cell Biol. 2014, 24, 44-52.

116. Neuspiel, M.; Schauss, A.C.; Braschi, E.; Zunino, R.; Rippstein, P.; Andrade-Navarro, M.A.; Rachubinski, R.A.; McBride, H.M. Cargo-selected transport from the mitochondria to peroxisomes is mediated by vesicular carriers. Curr. Biol. 2008, 18, 102-108.

117. Braschi, E.; Goyon, V.; Zunino, R.; Mohanty, A.; Xu, L.; McBride, H.M. Vps35 mediates vesicle transport between the mitochondria and peroxisomes. Curr. Biol. 2010, 20, 1310-1315.

118. Soubannier, V.; McLelland, G.L.; Zunino, R.; Braschi, E.; Rippstein, P.; Fon, E.A.; McBride, H.M. A vesicular transport pathway shuttles cargo from mitochondria to lysosomes. Curr. Biol. 2012, $22,135-141$.

119. Soubannier, V.; Rippstein, P.; Kaufman, B.A.; Shoubridge, E.A.; McBride, H.M. Reconstitution of mitochondria derived vesicle formation demonstrates selective enrichment of oxidized cargo. PLoS One 2012, 7, e52830.

120. Mohanty, A.; McBride, H.M. Emerging roles of mitochondria in the evolution, biogenesis, and function of peroxisomes. Front. Physiol. 2013, 4, doi:10.3389/fphys.2013.00268.

121. Sugiura, A.; McLelland, G.L.; Fon, E.A.; McBride, H.M. A new pathway for mitochondrial quality control: Mitochondrial-derived vesicles. EMBO J. 2014, 33, 2142-2156.

122. Calvo, S.E.; Mootha, V.K. The mitochondrial proteome and human disease. Annu. Rev. Genomics Hum. Genet. 2010, 11, 25-44.

123. Koopman, W.J.; Willems, P.H.; Smeitink, J.A. Monogenic mitochondrial disorders. N. Engl. J. Med. 2012, 366, 1132-1141.

124. Schiff, M.; Bénit, P.; Jacobs, H.T.; Vockley, J.; Rustin, P. Therapies in inborn errors of oxidative metabolism. Trends Endocrinol. Metab. 2012, 23, 488-495.

125. Ylikallio, E.; Suomalainen, A. Mechanisms of mitochondrial diseases. Ann. Med. 2012, 44, 41-59.

126. Lin, M.T.; Beal, M.F. Mitochondrial dysfunction and oxidative stress in neurodegenerative diseases. Nature 2006, 443, 787-795.

127. Fulda, S.; Galluzzi, L.; Kroemer, G. Targeting mitochondria for cancer therapy. Nat. Rev. Drug Discov. 2010, 9, 447-464. 
128. Szendroedi, J.; Phielix, E.; Roden, M. The role of mitochondria in insulin resistance and type 2 diabetes mellitus. Nat. Rev. Endocrinol. 2011, 8, 92-103.

129. Costa, V.; Scorrano, L. Shaping the role of mitochondria in the pathogenesis of Huntington's disease. EMBO J. 2012, 31, 1853-1864.

130. Wallace, D.C. Mitochondria and cancer. Nat. Rev. Cancer 2012, 12, 685-698.

131. Olszewska, A.; Szewczyk, A. Mitochondria as a pharmacological target: Magnum overview. IUBMB Life 2013, 65, 273-281.

132. Bratic, A.; Larsson, N.G. The role of mitochondria in aging. J. Clin. Investig. 2013, 123, 951-957.

133. López-Otín, C.; Blasco, M.A.; Partridge, L.; Serrano, M.; Kroemer, G. The hallmarks of aging. Cell 2013, 153, 1194-1217.

134. Barros, M.H.; da Cunha, F.M.; Oliveira, G.A.; Tahara, E.B.; Kowaltowski, A.J. Yeast as a model to study mitochondrial mechanisms in ageing. Mech. Ageing Dev. 2010, 131, 494-502.

135. Pan, Y. Mitochondria, reactive oxygen species, and chronological aging: A message from yeast. Exp. Gerontol. 2011, 46, 847-852.

136. Jazwinski, S.M. The retrograde response and other pathways of interorganelle communication in yeast replicative aging. Subcell. Biochem. 2012, 57, 79-100.

137. Longo, V.D.; Shadel, G.S.; Kaeberlein, M.; Kennedy, B. Replicative and chronological aging in Saccharomyces cerevisiae. Cell Metab. 2012, 16, 18-31.

138. Jazwinski, S.M. The retrograde response: When mitochondrial quality control is not enough. Biochim. Biophys. Acta 2013, 1833, 400-409.

139. Burstein, M.T.; Titorenko, V.I. A mitochondrially targeted compound delays aging in yeast through a mechanism linking mitochondrial membrane lipid metabolism to mitochondrial redox biology. Redox Biol. 2014, 2, 305-307.

140. Mirisola, M.G.; Longo, V.D. A radical signal activates the epigenetic regulation of longevity. Cell Metab. 2013, 17, 812-813.

141. Steinkraus, K.A.; Kaeberlein, M.; Kennedy, B.K. Replicative aging in yeast: The means to the end. Annu. Rev. Cell Dev. Biol. 2008, 24, 29-54.

142. Steffen, K.K.; Kennedy, B.K.; Kaeberlein, M. Measuring replicative life span in the budding yeast. J. Vis. Exp. 2009, 28, doi:10.3791/1209.

143. Kaeberlein, M. Lessons on longevity from budding yeast. Nature 2010, 464, 513-519.

144. Denoth Lippuner, A.; Julou, T.; Barral, Y. Budding yeast as a model organism to study the effects of age. FEMS Microbiol. Rev. 2014, 38, 300-325.

145. Goldberg, A.A.; Bourque, S.D.; Kyryakov, P.; Gregg, C.; Boukh-Viner, T.; Beach, A.; Burstein, M.T.; Machkalyan, G.; Richard, V.; Rampersad, S.; et al. Effect of calorie restriction on the metabolic history of chronologically aging yeast. Exp. Gerontol. 2009, 44, 555-571.

146. Longo, V.D.; Fabrizio, P. Chronological aging in Saccharomyces cerevisiae. Subcell. Biochem. 2012, 57, 101-121.

147. Piper, P.W. Maximising the yeast chronological lifespan. Subcell. Biochem. 2012, 57, 145-159.

148. Weissman, J.; Guthrie, C.; Fink, G.R. Guide to Yeast Genetics: Functional Genomics, Proteomics, and Other Systems Analysis, 2nd ed.; Academic Press: Burlington, CO, USA, 2010; p. 892.

149. Botstein, D.; Fink, G.R. Yeast: An experimental organism for 21 st Century biology. Genetics 2011, $189,695-704$. 
150. Sutphin, G.L.; Olsen, B.A.; Kennedy, B.K.; Kaeberlein, M. Genome-wide analysis of yeast aging. Subcell. Biochem. 2012, 57, 251-289.

151. Richard, V.R.; Bourque, S.D.; Titorenko, V.I. Metabolomic and lipidomic analyses of chronologically aging yeast. Methods Mol. Biol. 2014, 1205, 359-373.

152. Eisenberg, T.; Knauer, H.; Schauer, A.; Büttner, S.; Ruckenstuhl, C.; Carmona-Gutierrez, D.; Ring, J.; Schroeder, S.; Magnes, C.; Antonacci, L.; et al. Induction of autophagy by spermidine promotes longevity. Nat. Cell Biol. 2009, 11, 1305-1314.

153. Goldberg, A.A.; Bourque, S.D.; Kyryakov, P.; Boukh-Viner, T.; Gregg, C.; Beach, A.; Burstein, M.T.; Machkalyan, G.; Richard, V.; Rampersad, S.; et al. A novel function of lipid droplets in regulating longevity. Biochem. Soc. Trans. 2009, 37, 1050-1055.

154. Fontana, L.; Partridge, L.; Longo, V.D. Extending healthy life span-From yeast to humans. Science 2010, 328, 321-326.

155. Goldberg, A.A.; Richard, V.R.; Kyryakov, P.; Bourque, S.D.; Beach, A.; Burstein, M.T.; Glebov, A.; Koupaki, O.; Boukh-Viner, T.; Gregg, C.; et al. Chemical genetic screen identifies lithocholic acid as an anti-aging compound that extends yeast chronological life span in a TOR-independent manner, by modulating housekeeping longevity assurance processes. Aging 2010, 2, 393-414.

156. Kapahi, P; Chen, D.; Rogers, A.N.; Katewa, S.D.; Li, P.W.; Thomas, E.L.; Kockel, L. With TOR, less is more: A key role for the conserved nutrient-sensing TOR pathway in aging. Cell Metab. 2010, 11, 453-465.

157. Titorenko, V.I.; Terlecky, S.R. Peroxisome metabolism and cellular aging. Traffic 2011, 12, 252-259.

158. Beach, A.; Burstein, M.T.; Richard, V.R.; Leonov, A.; Levy, S.; Titorenko, V.I. Integration of peroxisomes into an endomembrane system that governs cellular aging. Front. Physiol. 2012, 3, doi:10.3389/fphys.2012.00283.

159. Beach, A.; Titorenko, V.I. Essential roles of peroxisomally produced and metabolized biomolecules in regulating yeast longevity. Subcell. Biochem. 2013, 69, 153-167.

160. De Cabo, R.; Carmona-Gutierrez, D.; Bernier, M.; Hall, M.N.; Madeo, F. The search for antiaging interventions: From elixirs to fasting regimens. Cell 2014, 157, 1515-1526.

161. Nyström, T.; Liu, B. Protein quality control in time and space-Links to cellular aging. FEMS Yeast Res. 2014, 14, 40-48.

162. Sinclair, D.A.; Guarente, L. Small-molecule allosteric activators of sirtuins. Annu. Rev. Pharmacol. Toxicol. 2014, 54, 363-380.

163. Hughes, A.L.; Gottschling, D.E. An early age increase in vacuolar pH limits mitochondrial function and lifespan in yeast. Nature 2012, 492, 261-265.

164. Jazwinski, S.M.; Kriete, A. The yeast retrograde response as a model of intracellular signaling of mitochondrial dysfunction. Front. Physiol. 2012, 3, doi:10.3389/fphys.2012.00139.

165. McFaline-Figueroa, J.R.; Vevea, J.; Swayne, T.C.; Zhou, C.; Liu, C.; Leung, G.; Boldogh, I.R.; Pon, L.A. Mitochondrial quality control during inheritance is associated with lifespan and mother-daughter age asymmetry in budding yeast. Aging Cell 2011, 10, 885-895.

166. Fehrmann, S.; Paoletti, C.; Goulev, Y.; Ungureanu, A.; Aguilaniu, H.; Charvin, G. Aging yeast cells undergo a sharp entry into senescence unrelated to the loss of mitochondrial membrane potential. Cell Rep. 2013, 5, 1589-1599. 
167. Knorre, D.A.; Popadin, K.Y.; Sokolov, S.S.; Severin, F.F. Roles of mitochondrial dynamics under stressful and normal conditions in yeast cells. Oxid. Med. Cell. Longev. 2013, 2013, doi:10.1155/2013/139491.

168. Sorokin, M.I.; Knorre, D.A.; Fedor, F.; Severin, F.F. Early manifestations of replicative aging in the yeast Saccharomyces cerevisiae. Microbial Cell 2014, 1, 37-42.

169. Higuchi, R.; Vevea, J.D.; Swayne, T.C.; Chojnowski, R.; Hill, V.; Boldogh, I.R.; Pon, L.A. Actin dynamics affect mitochondrial quality control and aging in budding yeast. Curr. Biol. 2013, 23, 2417-2422.

170. Nyström, T.; Liu, B. The mystery of aging and rejuvenation-A budding topic. Curr. Opin. Microbiol. 2014, 18, 61-67.

171. Vevea, J.D.; Swayne, T.C.; Boldogh, I.R.; Pon, L.A. Inheritance of the fittest mitochondria in yeast. Trends Cell Biol. 2014, 24, 53-60.

172. Heeren, G.; Rinnerthaler, M.; Laun, P.; von Seyerl, P.; Kössler, S.; Klinger, H.; Hager, M.; Bogengruber, E.; Jarolim, S.; Simon-Nobbe, B.; et al. The mitochondrial ribosomal protein of the large subunit, Afolp, determines cellular longevity through mitochondrial back-signaling via TOR1. Aging 2009, 1, 622-636.

173. Chen, X.J. The search for nonconventional mitochondrial determinants of aging. Mol. Cell 2011, 42, 271-273.

174. Perocchi, F.; Jensen, L.J.; Gagneur, J.; Ahting, U.; von Mering, C.; Bork, P.; Prokisch, H.; Steinmetz, L.M. Assessing systems properties of yeast mitochondria through an interaction map of the organelle. PLoS Genet. 2006, 2, e170.

175. Merz, S.; Westermann, B. Genome-wide deletion mutant analysis reveals genes required for respiratory growth, mitochondrial genome maintenance and mitochondrial protein synthesis in Saccharomyces cerevisiae. Genome Biol. 2009, 10, doi:10.1186/gb-2009-10-9-r95.

176. Caballero, A.; Ugidos, A.; Liu, B.; Öling, D.; Kvint, K.; Hao, X.; Mignat, C.; Nachin, L.; Molin, M.; Nyström, T. Absence of mitochondrial translation control proteins extends life span by activating sirtuin-dependent silencing. Mol. Cell 2011, 42, 390-400.

177. Yang, J.S.; Kim, J.; Park, S.; Jeon, J.; Shin, Y.E.; Kim, S. Spatial and functional organization of mitochondrial protein network. Sci. Rep. 2013, 3, doi:10.1038/srep01403.

178. Koppen, M.; Langer, T. Protein degradation within mitochondria: Versatile activities of AAA proteases and other peptidases. Crit. Rev. Biochem. Mol. Biol. 2007, 42, 221-242.

179. Baker, M.J.; Tatsuta, T.; Langer, T. Quality control of mitochondrial proteostasis. Cold Spring Harb. Perspect. Biol. 2011, 3, doi:10.1101/cshperspect.a007559.

180. Delaney, J.R.; Ahmed, U.; Chou, A.; Sim, S.; Carr, D.; Murakami, C.J.; Schleit, J.; Sutphin, G.L.; An, E.H.; Castanza, A.; et al. Stress profiling of longevity mutants identifies Afg3 as a mitochondrial determinant of cytoplasmic mRNA translation and aging. Aging Cell 2013, 12, 156-166.

181. Kissová, I.; Deffieu, M.; Manon, S.; Camougrand, N. Uth1p is involved in the autophagic degradation of mitochondria. J. Biol. Chem. 2004, 279, 39068-39074.

182. Bhatia-Kiššová, I.; Camougrand, N. Mitophagy in yeast: Actors and physiological roles. FEMS Yeast Res. 2010, 10, 1023-1034. 
183. Welter, E.; Montino, M.; Reinhold, R.; Schlotterhose, P.; Krick, R.; Dudek, J.; Rehling, P.; Thumm, M. Uth1 is a mitochondrial inner membrane protein dispensable for post-log-phase and rapamycin-induced mitophagy. FEBS J. 2013, 280, 4970-4982.

184. Burstein, M.T.; Kyryakov, P.; Beach, A.; Richard, V.R.; Koupaki, O.; Gomez-Perez, A.; Leonov, A.; Levy, S.; Noohi, F.; Titorenko, V.I. Lithocholic acid extends longevity of chronologically aging yeast only if added at certain critical periods of their lifespan. Cell Cycle 2012, 11, 3443-3462.

185. Bonawitz, N.D.; Chatenay-Lapointe, M.; Pan, Y.; Shadel, G.S. Reduced TOR signaling extends chronological life span via increased respiration and upregulation of mitochondrial gene expression. Cell Metab. 2007, 5, 265-277.

186. Pan, Y.; Shadel, G.S. Extension of chronological life span by reduced TOR signaling requires down-regulation of Sch9p and involves increased mitochondrial OXPHOS complex density. Aging 2009, 1, 131-145.

187. Pan, Y.; Schroeder, E.A.; Ocampo, A.; Barrientos, A.; Shadel, G.S. Regulation of yeast chronological life span by TORC1 via adaptive mitochondrial ROS signaling. Cell Metab. 2011, 13, 668-678.

188. Ocampo, A.; Liu, J.; Schroeder, E.A.; Shadel, G.S.; Barrientos, A. Mitochondrial respiratory thresholds regulate yeast chronological life span and its extension by caloric restriction. Cell Metab. 2012, 16, 55-67.

189. Fraenkel, D.G. Yeast Intermediary Metabolism; Cold Spring Harbor Laboratory Press: Cold Spring Harbor, NY, USA, 2011; p. 434.

190. Cai, L.; Tu, B.P. Driving the cell cycle through metabolism. Annu. Rev. Cell Dev. Biol. 2012, 28, 59-87.

191. Brandes, N.; Tienson, H.; Lindemann, A.; Vitvitsky, V.; Reichmann, D.; Banerjee, R.; Jakob, U. Time line of redox events in aging postmitotic cells. Elife 2013, 2, doi:10.7554/eLife.00306.

192. Kyryakov, P.; Beach, A.; Richard, V.R.; Burstein, M.T.; Leonov, A.; Levy, S.; Titorenko, V.I. Caloric restriction extends yeast chronological lifespan by altering a pattern of age-related changes in trehalose concentration. Front. Physiol. 2012, 3, doi:10.3389/fphys.2012.00256.

193. Beach, A.; Richard, V.R.; Leonov, A.; Burstein, M.T.; Bourque, S.D.; Koupaki, O.; Juneau, M.; Feldman, R.; Iouk, T.; Titorenko, V.I. Mitochondrial membrane lipidome defines yeast longevity. Aging 2013, 5, 551-574.

194. Schroeder, E.A.; Raimundo, N.; Shadel, G.S. Epigenetic silencing mediates mitochondria stress-induced longevity. Cell Metab. 2013, 17, 954-964.

195. Schroeder, E.A.; Shadel, G.S. Crosstalk between mitochondrial stress signals regulates yeast chronological lifespan. Mech. Ageing Dev. 2014, 135, 41-49.

196. Broach, J.R. Nutritional control of growth and development in yeast. Genetics 2012, 192, 73-105.

197. De Virgilio, C. The essence of yeast quiescence. FEMS Microbiol. Rev. 2012, 36, 306-339.

198. Crespo, J.L.; Powers, T.; Fowler, B.; Hall, M.N. The TOR-controlled transcription activators GLN3, RTG1, and RTG3 are regulated in response to intracellular levels of glutamine. Proc. Natl. Acad. Sci. USA 2002, 99, 6784-6789.

199. Powers, R.W.; Kaeberlein, M.; Caldwell, S.D.; Kennedy, B.K.; Fields, S. Extension of chronological life span in yeast by decreased TOR pathway signaling. Genes Dev. 2006, 20, $174-184$. 
200. Jewell, J.L.; Russell, R.C.; Guan, K.L. Amino acid signalling upstream of mTOR. Nat. Rev. Mol. Cell Biol. 2013, 14, 133-139.

201. Conrad, M.; Schothorst, J.; Kankipati, H.N.; van Zeebroeck, G.; Rubio-Texeira, M.; Thevelein, J.M. Nutrient sensing and signaling in the yeast Saccharomyces cerevisiae. FEMS Microbiol. Rev. 2014, 38, 254-299.

202. Shimobayashi, M.; Hall, M.N. Making new contacts: The mTOR network in metabolism and signalling crosstalk. Nat. Rev. Mol. Cell Biol. 2014, 15, 155-162.

203. Swinnen, E.; Ghillebert, R.; Wilms, T.; Winderickx, J. Molecular mechanisms linking the evolutionary conserved TORC1-Sch9 nutrient signalling branch to lifespan regulation in Saccharomyces cerevisiae. FEMS Yeast Res. 2014, 14, 17-32.

204. Wissing, S.; Ludovico, P.; Herker, E.; Büttner, S.; Engelhardt, S.M.; Decker, T.; Link, A.; Proksch, A.; Rodrigues, F.; Corte-Real, M.; et al. An AIF orthologue regulates apoptosis in yeast. J. Cell Biol. 2004, 166, 969-974.

205. Büttner, S.; Eisenberg, T.; Carmona-Gutierrez, D.; Ruli, D.; Knauer, H.; Ruckenstuhl, C.; Sigrist, C.; Wissing, S.; Kollroser, M.; Fröhlich, K.U.; et al. Endonuclease G regulates budding yeast life and death. Mol. Cell 2007, 25, 233-246.

206. Eisenberg, T.; Büttner, S.; Kroemer, G.; Madeo, F. The mitochondrial pathway in yeast apoptosis. Apoptosis 2007, 12, 1011-1023.

207. Pereira, C.; Silva, R.D.; Saraiva, L.; Johansson, B.; Sousa, M.J.; Côrte-Real, M. Mitochondria-dependent apoptosis in yeast. Biochim. Biophys. Acta 2008, 1783, 1286-1302.

208. Madeo, F.; Carmona-Gutierrez, D.; Ring, J.; Büttner, S.; Eisenberg, T.; Kroemer, G. Caspase-dependent and caspase-independent cell death pathways in yeast. Biochem. Biophys. Res. Commun. 2009, 382, 227-231.

209. Carmona-Gutierrez, D.; Eisenberg, T.; Büttner, S.; Meisinger, C.; Kroemer, G.; Madeo, F. Apoptosis in yeast: Triggers, pathways, subroutines. Cell Death Differ. 2010, 17, 763-773.

210. Sheibani, S.; Richard, V.R.; Beach, A.; Leonov, A.; Feldman, R.; Mattie, S.; Khelghatybana, L.; Piano, A.; Greenwood, M.; Vali, H.; et al. Macromitophagy, neutral lipids synthesis, and peroxisomal fatty acid oxidation protect yeast from "liponecrosis", a previously unknown form of programmed cell death. Cell Cycle 2014, 13, 138-147.

211. Richard, V.R.; Beach, A.; Piano, A.; Leonov, A.; Feldman, R.; Burstein, M.T.; Kyryakov, P.; Gomez-Perez, A.; Arlia-Ciommo, A.; Baptista, S.; et al. Mechanism of liponecrosis, a distinct mode of programmed cell death. Cell Cycle 2014, 13, 3707-3726.

212. Kanki, T.; Wang, K.; Cao, Y.; Baba, M.; Klionsky, D.J. Atg32 is a mitochondrial protein that confers selectivity during mitophagy. Dev. Cell 2009, 17, 98-109.

213. Okamoto, K.; Kondo-Okamoto, N.; Ohsumi, Y. Mitochondria-anchored receptor Atg32 mediates degradation of mitochondria via selective autophagy. Dev. Cell 2009, 17, 87-97.

214. Beach, A.; Titorenko, V.I. In search of housekeeping pathways that regulate longevity. Cell Cycle 2011, 10, 3042-3044.

215. Richard, V.R.; Leonov, A.; Beach, A.; Burstein, M.T.; Koupaki, O.; Gomez-Perez, A.; Levy, S.; Pluska, L.; Mattie, S.; et al. Macromitophagy is a longevity assurance process that in chronologically aging yeast limited in calorie supply sustains functional mitochondria and maintains cellular lipid homeostasis. Aging 2013, 5, 234-269. 
216. Cheng, X.; Ivessa, A.S. The migration of mitochondrial DNA fragments to the nucleus affects the chronological aging process of Saccharomyces cerevisiae. Aging Cell 2010, 9, 919-923.

217. Cheng, X.; Ivessa, A.S. Accumulation of linear mitochondrial DNA fragments in the nucleus shortens the chronological life span of yeast. Eur. J. Cell Biol. 2012, 91, 782-788.

218. Arlia-Ciommo, A.; Piano, A.; Svistkova, V.; Mohtashami, S.; Titorenko, V.I. Mechanisms underlying the anti-aging and anti-tumor effects of lithocholic bile acid. Int. J. Mol. Sci. 2014, 15, 16522-16543.

219. Beach, A.; Richard, V.R.; Bourque, S.; Boukh-Viner, T.; Kyryakov, P.; Gomez-Perez, A.; Arlia-Ciommo, A.; Feldman, R.; Leonov, A.; Piano, A.; et al. Lithocholic bile acid accumulated in yeast mitochondria orchestrates a development of an anti-aging cellular pattern by causing age-related changes in cellular proteome. Cell Cycle 2015, in press.

(C) 2015 by the authors; licensee MDPI, Basel, Switzerland. This article is an open access article distributed under the terms and conditions of the Creative Commons Attribution license (http://creativecommons.org/licenses/by/4.0/). 